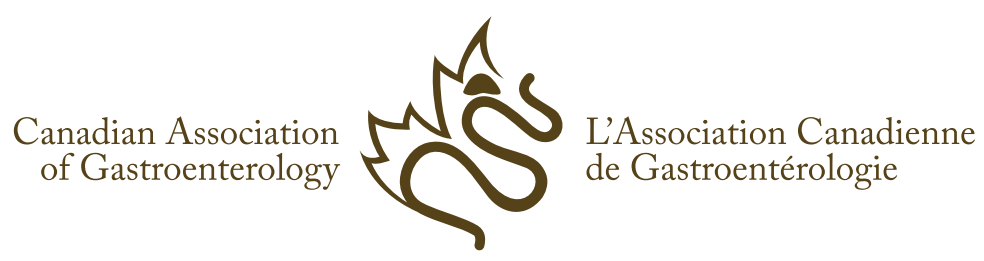

\title{
Canadian Association of Gastroenterology Fellow
}

$\mathrm{T}$ he Canadian Association of Gastroenterology Fellow (CAGF) distinction is an esteemed honour for CAG members who have demonstrated long-term commitment to the Association and to furthering the goals of advancing gastroenterology practice and research in Canada. The designation allows the person to use the CAGF suffix professionally. All other rights and requirements are those of a Regular member.

\section{ELIGIBILITY CRITERIA}

1) At least 10 years of continuous Regular membership in CAG, and with current membership in good standing. Membership history in other categories, such as Trainee or Affiliate, does not apply to the 10-year duration.

2) Demonstration of significant contribution to CAG through committee or executive work - with at least 5 years holding CAG positions. These years need not be consecutive.

3) Evidence of participation in (as participant and/or faculty) a minimum of 3 CME programs sponsored by the CAG (includes CDDW) within the last 5 years.

4) If a physician, Candidate shall have a full and unrestricted license to practice medicine in his/her respective province or territory, unless retired. Proof of licensure is required.

5) If not a physician, Candidate will have graduated from an accredited academic institution, and reached the rank of Associate or Full Professor or its equivalent. Proof of graduation of applicant's highest degree, and current position, is required.
The CAGF honour will be bestowed on the following CAG members on February 8, 2014 at Canadian Digestive Diseases Week in Toronto

\begin{tabular}{cc}
\hline \multicolumn{2}{c}{2014 INDUCTEES } \\
\hline Dr. Robert Bailey & Dr. Gary Levy \\
Edmonton, Alberta & Toronto, Ontario \\
Dr. Stephen Collins & Dr. William Paterson \\
Hamilton, Ontario & Kingston, Ontario \\
Dr. Carlo Fallone & Dr. Keith Sharkey \\
Montréal, Québec & Calgary, Alberta \\
Dr. Richard Hunt & Dr. Philip Sherman \\
Hamilton, Ontario & Toronto, Ontario \\
Dr. Jan Irvine & Dr. Connie Switzer \\
Toronto, Ontario & Edmonton, Alberta \\
Dr. Desmond Leddin & Dr. John Wallace \\
Halifax, Nova Scotia & Hamilton, Ontario \\
\hline
\end{tabular}

The CAG is proud to acknowledge its Benefactor Corporate Sponsors:

AbbVie Corporation

Olympus Canada Inc 


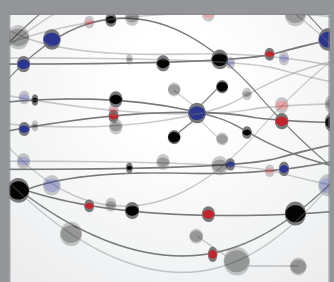

The Scientific World Journal
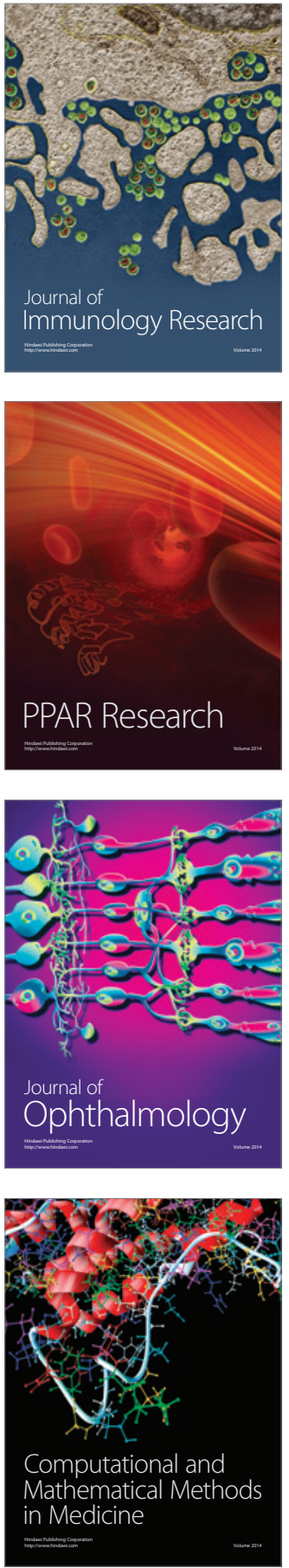

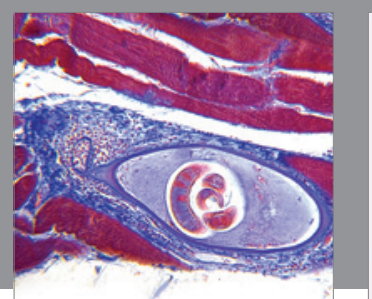

Gastroenterology Research and Practice

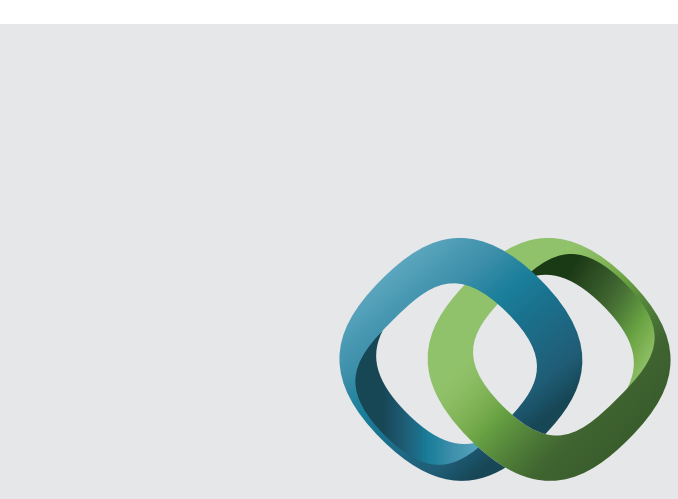

\section{Hindawi}

Submit your manuscripts at

http://www.hindawi.com
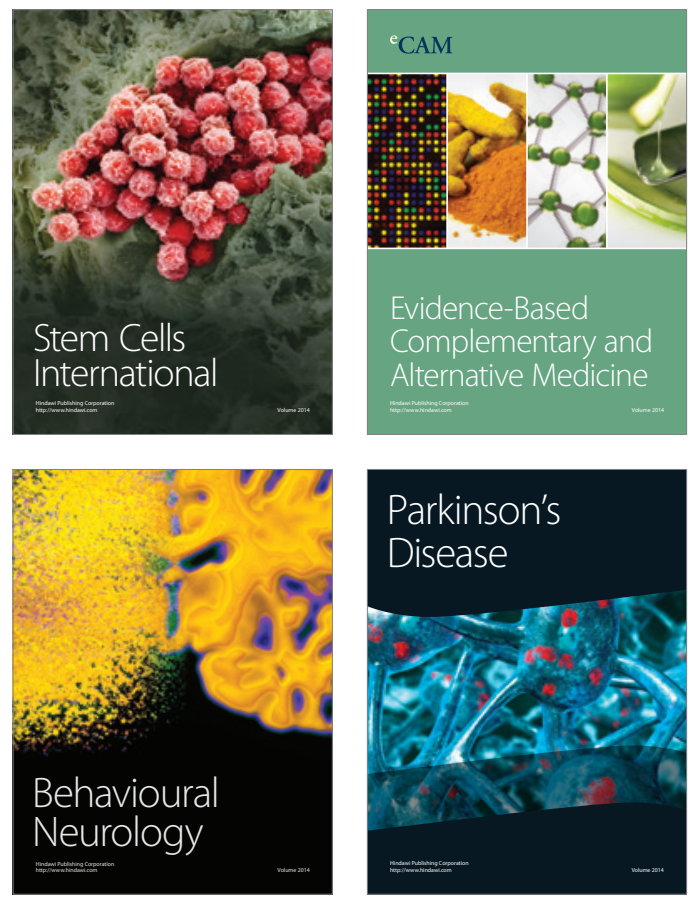
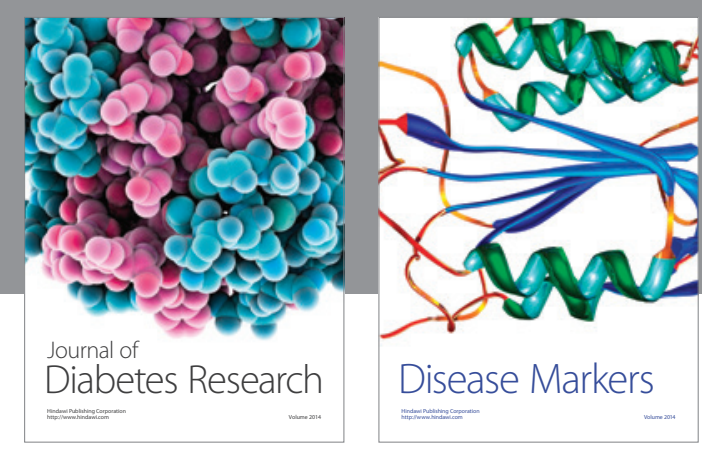

Disease Markers
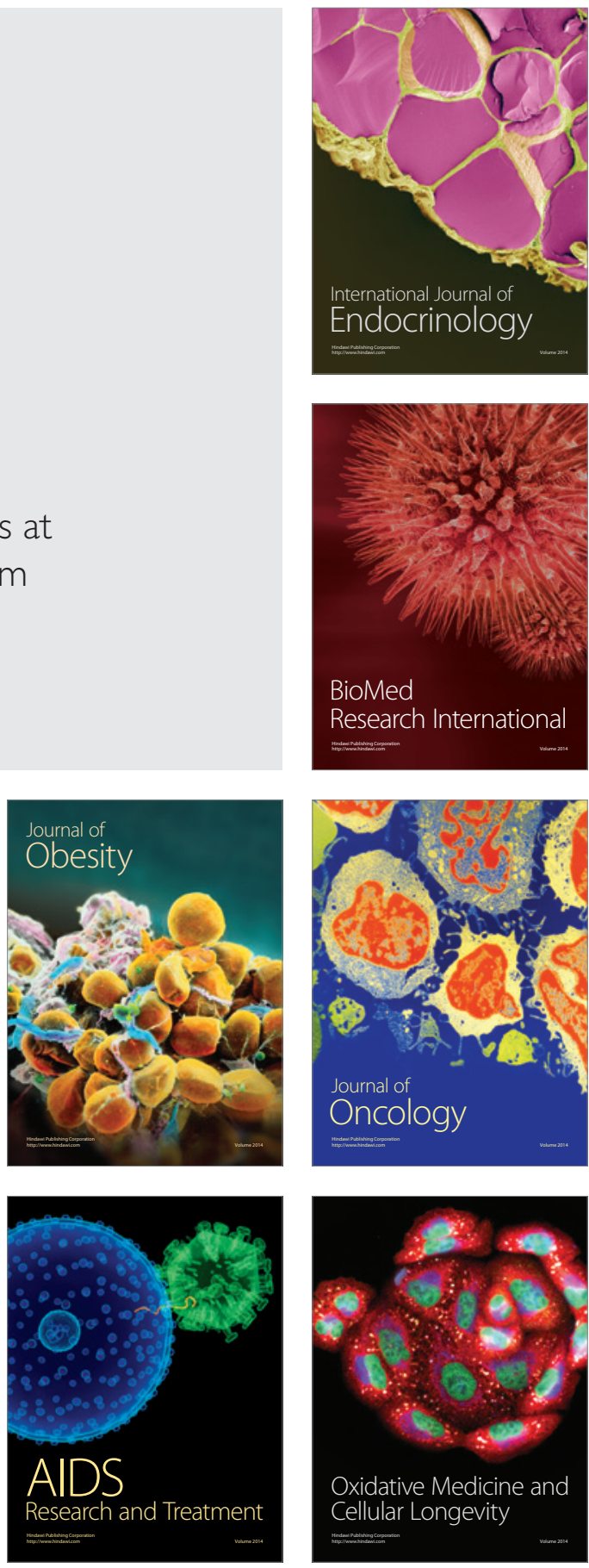